University of Nebraska - Lincoln

DigitalCommons@University of Nebraska - Lincoln

Faculty Papers and Publications in Animal

Science

Animal Science Department

February 1999

\title{
Genetic Parameters for Growth Traits for a Composite Terminal Sire Breed of Sheep
}

\author{
E. Mousa \\ University of Nebraska-Lincoln \\ L. Dale Van Vleck \\ University of Nebraska-Lincoln, dvan-vleck1@unl.edu \\ K. E. Leymaster \\ USDA, ARS, Roman L. Hruska U.S. Meat Animal Research Center
}

Follow this and additional works at: https://digitalcommons.unl.edu/animalscifacpub

Part of the Animal Sciences Commons

Mousa, E.; Van Vleck, L. Dale; and Leymaster, K. E., "Genetic Parameters for Growth Traits for a Composite Terminal Sire Breed of Sheep" (1999). Faculty Papers and Publications in Animal Science. 280.

https://digitalcommons.unl.edu/animalscifacpub/280

This Article is brought to you for free and open access by the Animal Science Department at DigitalCommons@University of Nebraska - Lincoln. It has been accepted for inclusion in Faculty Papers and Publications in Animal Science by an authorized administrator of DigitalCommons@University of Nebraska - Lincoln. 


\title{
Genetic Parameters for Growth Traits for a Composite Terminal Sire Breed of Sheep ${ }^{1}$
}

\author{
E. Mousa*,2, L. D. Van Vleckt,3, and K. A. Leymaster ${ }^{\ddagger}$ \\ *Department of Animal Science, University of Nebraska, Lincoln 68583-0908 and USDA, \\ ARS, Roman L. Hruska U.S. Meat Animal Research Center,

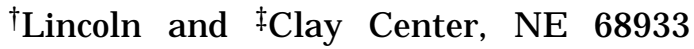

\begin{abstract}
Records of 9,055 lambs from a composite population originating from crossing Columbia rams to Hampshire $\times$ Suffolk ewes at the U.S. Meat Animal Research Center were used to estimate genetic parameters among growth traits. Traits analyzed were weights at birth (BWT), weaning ( 7 wk, WWT), 19 mo (W19), and 31 mo (W31) and postweaning ADG from 9 to 18 or $19 \mathrm{wk}$ of age. The ADG was also divided into daily gain of males (DGM) and daily gain of females (DGF). These two traits were analyzed with W19 and with W31 in three-trait analyses. (Co)variance components were estimated with REML for an animal model that included fixed effects of sex, age of dam, type of birth or rearing, and contemporary group. Random effects were direct and maternal genetic of animal and dam with genetic covariance, maternal permanent environmental, and random residual. Estimates of direct heritability were .09, .09, $.35, .44, .19, .16$, and .23 for BWT, WWT, W19, W31, ADG, DGM, and DGF, respectively. Estimates of maternal permanent environmental variance as a
\end{abstract}

proportion of phenotypic variance were $.09, .12, .03$, $.03, .03, .06$, and .02 , respectively. Estimates of maternal heritability were .17 and .09 for BWT and WWT and .01 to .03 for other traits. Estimates of genetic correlations were large among W19, W31, and ADG (.69 to .97), small between BWT and W31 or ADG, and moderate for other pairs of traits (.32 to .45). The estimate of genetic correlation between DGM and DGF was .94, and the correlation between maternal permanent environmental effects for these traits was .56. For the three-trait analyses, the genetic correlations of DGM and DGF with W19 were .69 and .82 and with W31 were .67 and .67, respectively. Results show that models for genetic evaluation for BWT and WWT should include maternal genetic effects. Estimates of genetic correlations show that selection for ADG in either sex can be from records of either sex (DGM or DGF) and that selection for daily gain will result in increases in mature weight but that BWT is not correlated with weight at 31 mo.

Key Words: Sheep, Genetic Correlation, Maternal Effects, Heritability

@1999 American Society of Animal Science All rights reserved.

J. Anim. Sci. 1999. 77:1659-1665

\section{Introduction}

Lamb weight and daily gain are important components of market lamb production. One way to increase meat output or achieve rapid growth and heavy market weight is by using terminal sire breeds. A composite population of sheep was formed at the U.S. Meat Animal Research Center (MARC) to produce such a terminal sire line (Leymaster, 1991).

Numerous studies have evaluated various sheep breeds as potential terminal sire breeds (Sidwell and

\footnotetext{
${ }^{1}$ Published as paper no. 12364, J ournal Ser., Nebraska Agric. Res. Div., Univ. of Nebraska, Lincoln 68583-0908. Financial support by the Egyptian government of the senior author is acknowledged.

${ }^{2}$ Current address: Faculty of Agric., Assiut Univ., 71516, Assiut, Egypt.
}

Miller, 1971a,b; Dickerson et al., 1974; Nitter, 1975a,b; Leymaster and Smith, 1981). For genetic evaluation and selection, genetic parameters for traits of importance should be known (e.g., Boujenane and Bradford, 1991). The objective of this study was to estimate variances and covariances due to direct genetic, maternal genetic, and maternal permanent environmental effects for five growth traits recorded on this composite population.

\footnotetext{
${ }^{3}$ To whom correspondence should be addressed: A218 Animal Sciences, Univ. of Nebraska, Lincoln 68583-0908 (phone: 402/ 472-6010; fax: 402/472-6362).

Received September 2, 1998.

Accepted February 25, 1999.
} 


\section{Materials and Methods}

The population was formed by mating Columbia rams to Hampshire $\times$ Suffolk ewes followed by inter se mating (Leymaster, 1991). The germ plasm of the composite population, therefore, from initiation was composed of $50 \%$ Columbia and $25 \%$ each of Hampshire and Suffolk inheritance. From 1983 through 1989, sires were randomly selected within paternal half-sib families. Thereafter, half of the sires were randomly selected, and half were selected for ADG. Analyzed data were recorded on sheep of the $F_{2}$ or more advanced generations of inter se mating. At least 20 sires were used each year, and paternal half-sib matings were avoided so that inbreeding accumulated slowly. The average inbreeding coefficient of the 3,389 inbred lambs was .019. A total of 295 sires and 2,709 dams were represented in the progeny.

Measurements for animals born from 1983 through 1995 were weight at birth (BWT), weight at weaning at approximately 7 wk of age ( $\mathbf{W} \mathbf{W}$ ), and postweaning ADG from 9 to 18 or 19 wk of age for both sexes combined and also for intact males (DGM) and females (DGF) analyzed separately. Weights at 19 mo ( W19) and at 31 mo ( W31) were for females only and were recorded prior to the breeding season. Ewes were kept on pasture during gestation with supplemental feed provided to meet nutrient requirements and lambed in drylot in a poleshed facility. Ram lambs were not castrated, and all lambs received a pelleted, total-mixed preweaning diet by $14 \mathrm{~d}$ of age. Weaning weight was adjusted to the average weaning age (50.64 d) by use of preweaning daily gain (PDG) of each lamb (WWT =BWT +PDG $\times 50.64)$. At about
9 wk of age, a total-mixed postweaning diet was offered for ad libitum consumption. Lambs remained in drylot until approximately 20 wk of age, when replacement ewes were turned out to pasture with access to supplemental feed. Management of sheep was consistent across years to the extent possible. Characteristics of the data are summarized in Table 1.

The MTDFREML programs of Boldman et al. (1993) were used for variance component estimation. Principles of derivative-free restricted maximum likelihood (MTDFREML) have been described by Smith and Graser (1986) and Meyer (1989) and reviewed in Boldman et al. (1993).

The general representation of the most complete animal model used is as follows:

$$
\mathbf{y}=\mathbf{X b}+\mathbf{Z}_{\mathrm{a}} \mathbf{a}+\mathbf{Z}_{\mathrm{m}} \mathbf{m}+\mathbf{Z}_{\mathrm{C}} \mathbf{c}+\mathbf{e},
$$

where

$\mathbf{y}$ is a $\mathrm{n} \times 1$ vector of records,

b denotes the fixed effects in the model with association matrix $\mathbf{X}$,

$\mathbf{a}$ is the vector of direct animal genetic effects with association matrix $\mathbf{Z}_{a}$,

$\mathbf{m}$ is the vector of maternal genetic effects with association matrix $\mathbf{Z}_{\mathrm{m}}$,

c is the vector of maternal permanent environmental effects with association matrix $\mathbf{Z}_{C}$, and

e denotes the vector of residual (temporary environmental) effects.

Fixed effects included in the model were sex, age of dam, type of birth or rearing, and contemporary

Table 1. Number of observations and mean (kg) for weight at birth (BWT), weaning (WWT), and 19 (W19) and 31 (W31) mo and postweaning gain for all lambs (ADG) and for males (DGM) and females (DGF) by level of fixed factors

\begin{tabular}{|c|c|c|c|c|c|c|c|c|c|c|c|c|c|c|}
\hline \multirow[b]{2}{*}{ Factor } & \multicolumn{2}{|c|}{ BWT } & \multicolumn{2}{|c|}{ WWT } & \multicolumn{2}{|c|}{ W19 } & \multicolumn{2}{|c|}{ W31 } & \multicolumn{2}{|c|}{ ADG } & \multicolumn{2}{|c|}{ DGM } & \multicolumn{2}{|c|}{ DGF } \\
\hline & No. & $\bar{x}$ & No. & $\bar{x}$ & No. & $\bar{x}$ & No. & $\bar{x}$ & No. & $\bar{x}$ & No. & $\bar{x}$ & No. & $\bar{x}$ \\
\hline Overall & 9,055 & 5.77 & 7,518 & 20.14 & 2,221 & 72.25 & 1,538 & 82.66 & 6,752 & .365 & 3,122 & .408 & 3,513 & .327 \\
\hline \multicolumn{15}{|l|}{ Sex } \\
\hline Male & 4,497 & 5.92 & 3,652 & 20.82 & - & - & - & - & 3,183 & .409 & 3,122 & .408 & 0 & - \\
\hline Female & 4,558 & 5.64 & 3,866 & 19.50 & 2,221 & 72.25 & 1,538 & 82.66 & 3,569 & .326 & 0 & - & 3,513 & .327 \\
\hline \multicolumn{15}{|c|}{ Age of dam, $y r$} \\
\hline 1 & 1,755 & 5.79 & 1,371 & 19.88 & 396 & 71.78 & 271 & 81.89 & 1,176 & .358 & 505 & .401 & 654 & .325 \\
\hline 2 & 3,147 & 5.68 & 2,618 & 19.97 & 731 & 72.07 & 486 & 83.65 & 2,408 & .366 & 1,152 & .408 & 1,232 & .327 \\
\hline 3 & 2,803 & 5.83 & 2,413 & 20.35 & 720 & 72.76 & 496 & 83.20 & 2,225 & .371 & 1,054 & .414 & 1,127 & .331 \\
\hline 4 & 1,203 & 5.88 & 991 & 20.55 & 324 & 72.91 & 246 & 83.15 & 819 & .364 & 364 & .410 & 426 & .323 \\
\hline 5 & 113 & 5.70 & 95 & 19.76 & 46 & 66.09 & 35 & 77.97 & 93 & .304 & 33 & .341 & 58 & .284 \\
\hline 6 & 34 & 5.92 & 30 & 18.56 & 4 & 70.00 & 4 & 78.98 & 31 & .346 & 14 & .404 & 16 & .303 \\
\hline \multicolumn{15}{|c|}{ Type of birth (BWT) or rearing (no.) } \\
\hline 1 & 2,859 & 6.45 & 3,147 & 22.05 & 936 & 72.98 & 645 & 83.64 & 2,733 & .364 & 1,257 & .408 & 1,477 & .325 \\
\hline 2 & 5,286 & 5.57 & 4,188 & 18.82 & 1,212 & 71.36 & 843 & 81.93 & 3,734 & .366 & 1,791 & .408 & 1,943 & .327 \\
\hline 3 & 773 & 4.80 & 179 & 17.48 & 55 & 74.12 & 37 & 82.94 & 163 & .374 & 72 & .412 & 91 & .344 \\
\hline 4 & 32 & 4.15 & 4 & 19.61 & $18^{\mathrm{a}}$ & 67.30 & $13^{a}$ & 80.63 & 4 & .401 & 2 & .445 & 2 & .357 \\
\hline 5 & 5 & 4.18 & - & - & - & - & - & - & $188^{\mathrm{a}}$ & .332 & - & - & - & - \\
\hline
\end{tabular}

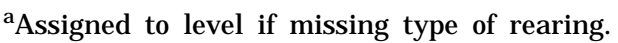


Table 2. Components of models used for each trait (analyses with two or three traits) ${ }^{a}$

\begin{tabular}{|c|c|c|c|c|c|c|c|}
\hline Factor & BWT & WWT & W19 & W31 & ADG & DGF & DGM \\
\hline \multicolumn{8}{|l|}{ Fixed } \\
\hline Type of birth & $x$ & & & & & & \\
\hline Contemporary group & $\mathrm{x}$ & $x$ & $x$ & $x$ & $\mathrm{x}$ & $x$ & $\mathrm{x}$ \\
\hline Type of rearing & & $x$ & $x$ & $x$ & $x$ & $x$ & $\mathrm{x}$ \\
\hline Sex & $\mathrm{x}$ & $\mathrm{x}$ & & & $\mathrm{x}$ & & \\
\hline Age of dam & $\mathrm{x}$ & $\mathrm{x}$ & $\mathrm{x}$ & $\mathrm{x}$ & $\mathrm{x}$ & $\mathrm{x}$ & $\mathrm{x}$ \\
\hline \multicolumn{8}{|l|}{ Random } \\
\hline Direct genetic & $x$ & $x$ & $x$ & $x$ & $x$ & $x$ & $\mathrm{x}$ \\
\hline Maternal genetic & $\mathrm{x}$ & $x$ & & & & & \\
\hline Maternal permanent environmental ${ }^{b}$ & $\mathrm{x}$ & $\mathrm{x}$ & $x$ & $\mathrm{x}$ & $\mathrm{x}$ & $x$ & $x$ \\
\hline Temporary environmental & $\mathrm{x}$ & $\mathrm{x}$ & $x$ & $\mathrm{x}$ & $x$ & $x$ & $\mathrm{x}$ \\
\hline
\end{tabular}

${ }^{\text {aBWT }}=$ weight at birth, WWT $=$ weight at weaning, W19 = weight at 19 mo, W31 = weight at 31 mo, ADG = postweaning average daily gain, DGF = daily gain for females, and DGM = daily gain for males.

b'Combined maternal genetic and permanent environmental if maternal genetic was not in the model.

groups (Table 2). Effects were estimated with singletrait analyses.

The variance-covariance structure for a trait with this model is as follows:

$$
\mathrm{V}\left[\begin{array}{l}
\mathbf{a} \\
\mathbf{m} \\
\mathbf{c} \\
\mathbf{e}
\end{array}\right]=\left[\begin{array}{llll}
\mathbf{A} \sigma_{\mathrm{a}}^{2} & \mathbf{A} \sigma_{\mathrm{am}} & 0 & 0 \\
\mathbf{A} \sigma_{\mathrm{am}} & \mathbf{A} \sigma_{\mathrm{m}}^{2} & 0 & 0 \\
0 & 0 & \mathbf{I}_{\mathrm{c}} \sigma_{\mathrm{c}}^{2} & 0 \\
0 & 0 & 0 & \mathbf{I}_{\mathrm{n}} \sigma_{\mathrm{e}}^{2}
\end{array}\right]
$$

where

A is the numerator relationship matrix,

$\mathbf{I}_{\mathrm{C}}$ is an identity matrix with order number of dams;

$\mathbf{I}_{\mathrm{n}}$ is an identity matrix with order number of records,

$\sigma_{a}^{2}$ is direct genetic variance,

$\sigma_{\mathrm{m}}^{2}$ is maternal genetic variance,

$\sigma_{\mathrm{am}}$ is covariance between direct and maternal genetic effects,

$\sigma_{c}^{2}$ is variance due to maternal permanent en-

$c$ vironmental effects, and

$\sigma_{\mathrm{e}}^{2}$ is variance due to residual (temporary environmental) effects.

Estimates from single-trait analyses used to obtain starting values for two- and threetrait analyses also provided a reason to drop maternal genetic effects from the models for traits measured after weaning. For those traits, an uncorrelated dam effect was included, however, to account for a combination of maternal genetic and permanent environmental effects.

Type of rearing ( $\mathbf{T R}$ ) was defined as the number of lambs nursed by the ewe halfway to weaning age. That is, if weaning occurred at $50 \mathrm{~d}$, type of rearing was the number of lambs the ewe was rearing at $25 \mathrm{~d}$. Because TR refers only to the status before weaning, TR is the same for modeling WWT, W19, W31, and daily gain. To avoid discarding the data when TR was missing, a new classification was added to TR to include those animals. All weights were analyzed with type of rearing as a fixed factor, except for BWT, for which type of birth was included in the model. Contemporary groups were formed differently for different traits. A contemporary group for BWT, W19, and W31 was composed of sheep born in a given lambing band corresponding to a specific 35-d breeding season. A contemporary group for WWT was defined by date of weaning, whereas contemporary group for ADG was defined by date of first postweaning weight at approximately $9 \mathrm{wk}$ of age.

Five different combinations of random effects in the models were used to analyze pairs of traits (Table 2 ). Bivariate analyses were done because of computational limitations. Robison (1981) concluded that maternal genetic effects are important in early growth of most mammals. Therefore, maternal effects were included as indicated unless maternal effects were shown to be unimportant from analyses of single traits. With the full animal model, covariances between direct genetic effects, between maternal genetic effects, between maternal permanent environmental effects, and between temporary environmental effects were estimated for BWT and WWT. The random component corresponding to maternal genetic effects on W19, W31, or ADG was dropped from the model for bivariate analyses with BWT or WWT. For bivariate analyses among W19, W31, and ADG, the model did not include maternal genetic effects for either trait. When the two traits were a trait measured on one sex and the same trait measured on the other sex (DGM, DGF), the covariance between the residual effects was zero. The model used for three-trait analyses (W19, DGM, DGF or W31, DGM, DGF) did not include maternal genetic effects, and two of the three residual covariances had to be equal to zero. The residual covariance between daily gain for a female and W19 or W31 (measured only on females) could be different from zero. 
Although not the primary interest of this study, Table 3 lists estimates of differences between levels of the fixed effects from single-trait analyses with tests of significance according to a t-test with comparisonwise error rates. The patterns of estimated differences are as expected (e.g., Ercanbrack and Price, 1972, 1977; Stobart et al., 1986).

\section{Results and Discussion}

\section{Single-Trait Analyses}

Estimates of variances and covariances relative to phenotypic variance for BWT, WWT, W19, W31, and ADG are shown in Table 4 for single-trait analyses. Relative variances due to direct genetic effects $\left(h^{2}\right)$ were .09 for BWT and WWT with relative variances due to maternal genetic effects $\left(\mathrm{m}^{2}\right)$ of .17 and .09 , respectively. Notter (1998) reported estimates for Polypay sheep for 60-d weaning weights similar to those reported here but larger direct heritability (.19) and smaller maternal heritability (.04) for Suffolk sheep. From an analysis of Targhee weaning weights, Notter and Hough (1997) estimated $h^{2}$ to be .07 and $\mathrm{m}^{2}$ to be .19 under intensive management. The current estimates of $\mathrm{h}^{2}$ for BWT and WWT are larger than estimates of .02 (BWT) and .04 for (WWT) by Khaldi and Boichard (1989) for Barbary lambs. Waldron et al. (1990) reported heritability estimates for BWT and WWT in crossbred lambs (Suffolk, Dorset, and Rambouillet) of .13 and .09, respectively. Mavrogenis et al. (1980), working with Chios sheep, estimated $h^{2}$ for the same traits to be .13 and .12, respectively. The average $h^{2}$ in the review by Fogarty (1995) was approximately .20 for dual-purpose and meat breeds.

Estimates of $\mathrm{h}^{2}$ for W19, W31, and ADG were in the moderate range and within the range of estimates reported in literature (e.g., Ercanbrack and Price, 1972; Olson et al., 1976; Gupta et al., 1983; Mousa, 1989; Fogarty, 1995). Body weights at 19 and 31 mo and ADG had low estimates of maternal heritability of $.01, .03$, and .01, respectively. The maternal heritability estimates suggest that genetic maternal effects are not important for weights or gain at older ages.

When the variances of maternal effects are near zero, the covariance between direct and maternal effects $\left(r_{a m}\right)$ has little meaning. In general, there seems to be an antagonism between direct genetic and

Table 3. Estimates of differences between levels of fixed factors $(\mathrm{kg})^{\mathrm{a}}$

\begin{tabular}{|c|c|c|c|c|c|}
\hline Trait/contrast & BWT & WWT & W19 & W31 & ADG \\
\hline \multicolumn{6}{|l|}{ Sex } \\
\hline Male-female & $.286^{*}$ & $1.35^{*}$ & - & - & $.0771^{*}$ \\
\hline \multicolumn{6}{|c|}{ Age of dam, yr } \\
\hline $1-2$ & $-.531 *$ & $-2.22 *$ & $-1.50 *$ & $-2.47^{*}$ & .0036 \\
\hline $1-3$ & $-.885^{*}$ & $-3.43^{*}$ & $-2.26 *$ & $-3.26 *$ & $-.0041^{*}$ \\
\hline $1-4$ & $-.930 *$ & $-3.40 *$ & $-3.02 *$ & $-3.47^{*}$ & -.0032 \\
\hline $1-5$ & $-.934^{*}$ & $-3.35^{*}$ & $-3.07 *$ & $-2.34 *$ & -.0036 \\
\hline $1-6$ & -.975 & $-2.70^{*}$ & -2.77 & 0 & -.0136 \\
\hline $2-3$ & -.354 & $-1.17^{*}$ & $-.76^{*}$ & $-.79 *$ & $-.0050^{*}$ \\
\hline $2-4$ & $-.399 *$ & $-1.14^{*}$ & $-1.52 *$ & $-1.01^{*}$ & $-.0045^{*}$ \\
\hline $2-5$ & $-.404^{*}$ & $-1.08^{*}$ & -1.58 & .12 & .0018 \\
\hline $2-6$ & $-.445^{*}$ & -.42 & -1.27 & 2.47 & -.0181 \\
\hline $3-4$ & -.045 & .03 & -.76 & -.21 & .0009 \\
\hline $3-5$ & -.050 & .08 & -.82 & .92 & .0091 \\
\hline $3-6$ & -.091 & .75 & -.51 & 3.26 & -.0091 \\
\hline $4-5$ & -.005 & .05 & -.06 & 1.13 & .0064 \\
\hline $4-6$ & -.045 & .72 & .25 & 3.47 & .0136 \\
\hline $5-6$ & -.041 & .67 & .31 & 2.34 & -.0181 \\
\hline \multicolumn{6}{|c|}{ Type of birth or rearing (no.) } \\
\hline $1-2$ & 1.192* & $4.29 *$ & $2.45^{*}$ & 2.88 & -.0001 \\
\hline $1-3$ & $1.905^{*}$ & 5.66 & $2.21 *$ & $3.44 *$ & -.0023 \\
\hline $1-4$ & $2.431^{*}$ & 4.21 & - & - & -.0136 \\
\hline $1-5$ & $2.486 *$ & - & - & - & - \\
\hline $2-3$ & $.708^{*}$ & $1.37 *$ & -.24 & .56 & -.0018 \\
\hline $2-4$ & $1.238 *$ & -.08 & - & - & -.0136 \\
\hline $2-5$ & $1.293^{*}$ & - & - & - & - \\
\hline $3-4$ & $.531^{*}$ & -1.45 & - & - & -.0091 \\
\hline $3-5$ & .585 & - & - & - & - \\
\hline $4-5$ & .054 & - & - & - & - \\
\hline
\end{tabular}

${ }^{\mathrm{a}} \mathrm{BWT}=$ weight at birth, WWT $=$ weight at weaning, $\mathrm{W} 19=$ weight at $19 \mathrm{mo}, \mathrm{W} 31=$ weight at $31 \mathrm{mo}$, and $A D G=$ postweaning average daily gain.

*Significantly different from zero ( $\mathrm{P} \leq .05)$. 
Table 4. Estimates of genetic parameters from single-trait analyses of weight $(\mathrm{kg})$ at birth (BWT), weaning (WWT), 19 mo (W19), and 31 mo (W31) and postweaning average daily gain $(\mathrm{ADG})^{\mathrm{a}}$

\begin{tabular}{lllllc}
\hline \hline Trait & $\mathrm{h}^{2}$ & $\mathrm{~m}^{2}$ & $\mathrm{r}_{(\mathrm{a}, \mathrm{m})}$ & $\mathrm{c}^{2}$ & $\sigma_{\mathrm{p}}^{2}$ \\
\hline BWT & .09 & .17 & .01 & .09 & 1.02 \\
WWT & .09 & .09 & -.39 & .12 & 14.64 \\
WT19 & .26 & .01 & 1.00 & .02 & 42.27 \\
WT31 & .45 & .03 & -.12 & .00 & 51.68 \\
ADG & .21 & .01 & -.52 & .03 & .005 \\
\hline \multicolumn{2}{c}{$\mathrm{a}^{2}=$ direct heritability, $\mathrm{m}^{2}=$ maternal heritability, $\mathrm{r}_{\mathrm{a}, \mathrm{m}}=$ direct-maternal genetic correlation, $\mathrm{c}^{2}=$} \\
relative variance due to maternal permanent environmental effects, and $\sigma_{\mathrm{p}}^{2}=$ phenotypic variance.
\end{tabular}

maternal genetic effects (Robison, 1981), especially for weaning weight, in agreement with the directmaternal genetic correlation of -.39 from this analysis. Maria et al. (1993) reported negative direct-maternal correlations for BWT, WWT, and ADG of $-.99,-.98$, and -.99 , respectively. Khaldi and Boichard (1989) reported estimates of $r_{a m}$ traits in Barbary lambs of -.62 or even more negative for birth and weaning weights. Notter (1998) found a range of estimates for $r_{\text {am }}$ depending on weaning date. For $60-d$ weights, the estimates of $r_{a m}$ were -.42 for Suffolk and -.55 for Polypay for single-trait analyses but smaller for bivariate analyses involving 30- and 60-d weights ( -.20 and -.35 for Suffolk and Polypay). Shi et al. (1992) also reported high negative estimates of $r_{a m}$ working with Limousin field data. Eler et al. (1992) reported estimates of $r_{a m}$ for 205- and 365-d weights in Nelore cattle that were as large as -.91. Bennett and Gregory (1996), however, reported near-zero estimates of $r_{a m}$ for composite breeds of cattle for birth and weaning weights. The antagonism between an animal's direct genetic effect and that of the dam for maternal genetic might be due to natural selection for an intermediate optimum (Tosh and Kemp, 1994). Cundiff (1972) postulated that from an evolutionary standpoint the relationship is negative and, hence, prevents species from becoming increasingly larger. Extremely high values of $r_{a m}$, however, seem biologically unlikely.

Estimates of fraction of variance due to maternal permanent environmental effects $\left(c^{2}\right)$ were .09 for BWT and .12 for WWT. Notter (1998) reported estimates of $c^{2}$ for 60 -d weight of .12 for Suffolk and .15 for Polypay. The estimate for Targhee by Notter and Hough (1997) was also higher, .19. The differences in estimates of $c^{2}$ between WWT and W19, W30, or ADG reflect that suckling lambs are still dependent on their dams, whereas, after weaning, a lamb's growth rate is dependent on its own genetic potential for growth, and subsequent weights are only minimally influenced by either maternal genetic or maternal permanent environmental effects, except for carry-over effects.

\section{Two-Trait Analyses}

Estimates of direct heritability (averages of twotrait analyses) and direct genetic and phenotypic correlations among traits are presented in Table 5. Estimates of variance components for direct genetic, maternal genetic, and maternal permanent environmental effects were essentially the same as from the single-trait analyses.

The largest positive relationships were between chronologically adjacent weight traits rather than nonadjacent ones. This result is expected because an autocorrelation would exist among the genetic and environmental effects associated with the measurements (e.g., Mansour, 1982). The largest genetic correlation between weights was between W19 and W31 (.97). The genetic correlation between ADG and W19 was .78 and between ADG and W31 was .69. The absence of genetic antagonisms among the various traits indicates that none of the traits should be affected adversely through correlated responses. The large genetic correlations suggest that selecting for rapid growth without changing mature weight would be difficult.

Estimates of correlations between maternal genetic effects for BWT and direct genetic effects for BWT, WWT, W19, W31, and ADG were positive but near

Table 5. Estimates of genetic (above the diagonal) and phenotypic (below the diagonal) correlations among birth weight (BWT), weaning weight (WWT), 19-mo weight (W19), 31-mo weight (W31), and postweaning average daily gain

(ADG). Direct heritability estimates are on the diagonal ${ }^{\text {a }}$

\begin{tabular}{lccccc}
\hline \hline Trait & BWT & WWT & W19 & W31 & ADG \\
\hline BWT & .09 & .45 & .35 & -.01 & -.02 \\
WWT & .43 & .09 & .43 & .32 & .37 \\
W19 & .27 & .34 & .35 & .97 & .78 \\
W31 & .39 & .30 & .65 & .44 & .69 \\
ADG & .13 & .16 & .34 & .37 & .19 \\
\hline
\end{tabular}

${ }^{\text {a} A v e r a g e s ~ o f ~ e s t i m a t e s ~ f r o m ~ f o u r ~ t w o-t r a i t ~ a n a l y s e s . ~}$ 
Table 6. Correlations between maternal genetic effects of BWT and WWT and direct genetic effects at different weights ${ }^{\mathrm{a}}$

\begin{tabular}{lcc}
\hline \hline & \multicolumn{2}{c}{ Maternal genetic } \\
\cline { 2 - 3 } Direct genetic & BWT & WWT \\
\hline BWT & .01 & -.12 \\
WWT & .05 & -.39 \\
W19 & .36 & .10 \\
W31 & .00 & .00 \\
ADG & .01 & .02 \\
\hline
\end{tabular}

aBWT $=$ weight at birth, WWT $=$ weight at weaning, W19 = weight at $19 \mathrm{mo}, \mathrm{W} 31=$ weight at $31 \mathrm{mo}$, and ADG = postweaning average daily gain.

zero except for W19 (.36, Table 6). The correlations between maternal genetic effects for WWT and direct genetic effects for the same traits were also small, except for WWT itself (-.39). The estimated genetic correlation between maternal genetic effects for BWT and WWT was high (.51, not tabulated).

Estimates of relative variances and correlations among maternal permanent environmental effects $\left(c^{2}\right)$ for BWT, WWT, W19, W31, and ADG are shown in Table 7. The estimate of $c^{2}$ for BWT was the same as that noted by Maria et al. (1993). Other estimates of $c^{2}$ also were similar to those of Maria et al. (1993) for the remaining traits, except for WWT, for which $c^{2}$ was larger than their estimate of zero.

Correlations between maternal permanent environmental effects, or dam effects when maternal effects were not partitioned, for different weight traits were highly positive and ranged from .57 between maternal permanent environmental effects for BWT and WWT to .99 for other pairs of traits. Correlations between maternal permanent environmental effects for ADG and for birth and weaning weights (.40 and .49) were different from those for ADG with 19- and 31-mo weights (.09 and .08). The maternal permanent environmental variances accounted for only .03 of total variance for weights after weaning. Because the variance of maternal permanent environmental effects was so small for ADG, the correlations between maternal permanent environmental effects for ADG and other weights seem to have little meaning.

\section{Three-Trait Analyses}

Table 8 summarizes estimates of parameters for direct genetic and unpartitioned maternal effects from three-trait analyses (W19, DGM, and DGF) and (W31, DGM, and DGF). The relative estimates of variance components for DGM and DGF averaged about the same as for ADG, which included records of both DGM and DGF. The heritability for DGF (.23) was greater than that for DGM (.16). The phenotypic variance was the same for DGF and DGM. The estimated genetic correlation between direct genetic
Table 7. Estimates of relative variance due to maternal permanent environmental effects (on diagonal) and correlations among them (above the diagonal) for different weight traits ${ }^{\mathrm{a}}$

\begin{tabular}{lccccc}
\hline \hline Trait & BWT & WWT & W19 & W31 & ADG \\
\hline BWT & .10 & .57 & .99 & .99 & .40 \\
WWT & & .12 & .99 & .99 & .49 \\
W19 & & & .03 & .99 & .09 \\
W31 & & & & .03 & .08 \\
ADG & & & & & .03 \\
\hline
\end{tabular}

${ }^{\text {aBWT }}=$ weight at birth, WWT $=$ weight at weaning, W19 = weight at $19 \mathrm{mo}, \mathrm{W} 31=$ weight at $31 \mathrm{mo}$, and ADG = postweaning average daily gain.

effects for DGM and DGF was .94. These estimates suggest that gain in males and females can be considered to be one trait. The genetic correlations with W19 were large and similar for DGF $(.82)$ and DGM (.69) and for W31 with DGF (.67) and DGM (.67). The correlation between maternal effects for DGM and DGF was .56. The correlation between maternal effects for gain and W31 in Table 7 of .08 was smaller than that between DGM and W31 (.67) and between DGF and W31 (.23). The same pattern, although less extreme, also appeared for W19 with gain (.22 and .04 vs .09). Whether this discrepancy is due to sampling variance or to some aspect of modeling two- vs three-trait analyses is not clear.

\section{Implications}

Heritabilities are large enough that selection would be effective for improving any of the growth traits. Selection for greater weaning weight would need to

Table 8. Estimates of fractional variances (diagonals) and correlations across traits due to direct genetic effects and due to maternal effects from three-trait analyses of weight at 19 mo (W19), postweaning daily gain in males (DGM) and in females (DGF), and of weight at 31 mo (W31) with DGM and DGF

\begin{tabular}{|c|c|c|c|c|}
\hline Trait & W19 & W31 & DGM & DGF \\
\hline & \multicolumn{4}{|c|}{ Direct genetic effects } \\
\hline W19 & .35 & .97 & .69 & .82 \\
\hline W31 & & .44 & .67 & .67 \\
\hline DGM & & & .16 & .94 \\
\hline \multirow[t]{2}{*}{ DGF } & & & & .23 \\
\hline & & \multicolumn{2}{|c|}{ Maternal effects } & \\
\hline W19 & .03 & .99 & .22 & .04 \\
\hline W31 & & .03 & .67 & .23 \\
\hline DGM & & & .06 & .56 \\
\hline DGF & & & & .02 \\
\hline
\end{tabular}


consider maternal genetic and maternal permanent environmental effects as well as the negative genetic correlation between direct and maternal effects. Estimates of genetic correlations show that selection for weaning weight would also increase birth weight, weight at 19 and $31 \mathrm{mo}$, and, by implication, mature weight. Similarly, selection for gain from 9 to $18 \mathrm{wk}$ of age would be effective and not complicated by maternal effects. Such selection should increase mature weight and have little effect on birth weight. The genetic correlation between average daily gain in females and males of .94 indicates that selection based on gain in either sex would be effective for improving gain in both sexes.

\section{Literature Cited}

Bennett, G. L., and K. E. Gregory. 1996. Genetic (co)variances among birth weight, 200-day weight, and postweaning gain in composites and parental breeds of beef cattle. J . Anim. Sci. 74: 2598-2611.

Boldman, K. G., L. A. Kriese, L. D. Van Vleck, and S. D. Kachman. 1993. A Manual for use of MTDFREML. A set of programs to obtain estimates of variances and covariances [DRAFT]. USDA, ARS, Washington, DC.

Boujenane, I., and G. E. Bradford. 1991. Genetic effects on ewe productivity of crossing D'Man and Sardi breeds of sheep. J . Anim. Sci. 69:525-530.

Cundiff, L. V. 1972. The role of maternal effects in animal breeding: VIII. Comparative aspects of maternal effects. J. Anim. Sci. 35: 1335-1337.

Dickerson, G. E., J . Crouse, H. A. Glimp, and K. E. Gregory. 1974. Carcass traits of market lambs from Finn-cross ewes. J. Anim. Sci. 39:143 (Abstr.).

Eler, J. P., J B.S. Ferraz, R. B. Lobo, and L. A. J osakian. 1992. Genetic antagonism between growth and maternal ability in Nelore cattle. J. Anim. Sci. 70:(Suppl.1):138 (Abstr.).

Ercanbrack, S. K., and D. A. Price. 1972. Selecting for weight and rate of gain in noninbred lambs. J. Anim. Sci. 34:713-725.

Ercanbrack, S. K., and D. A. Price. 1977. Selecting for weight and rate of gain in inbred lambs. J. Anim. Sci. 44:532-541.

Fogarty, N. M. 1995. Genetic parameters for live weight, fat and muscle measurements, wool production and reproduction in sheep: A review. Anim. Breed Abstr. 63:101-143.

Gupta, R. N., C. M. Taylor, and K. S. J ohar. 1983. Genetic and non genetic factors effecting body weight at various age in Bikaneri sheep. Anim. Breed. Abstr. No. 2558.

Khaldi, G., and D. Boichard. 1989. Direct and maternal effects on the growth characters in the Barbary sheep breed. Ann. Inst. Natl. Rech. Agron. Tunis. 62(2):3.

Leymaster, K. A. 1991. Straightbred comparison of a composite population and the Suffolk breed for performance traits of sheep. J. Anim. Sci. 69:993-999.
Leymaster, K. A., and G. M. Smith. 1981. Columbia and Suffolk terminal sire breed effects. J. Anim. Sci. 53:1225-1235.

Mansour, H. 1982. Analysis of covariance structures in repeated measures designs with reference to estimation of repeatability. Ph.D. thesis. Univ. of Wisconsin, Madison.

Maria, G. A., K. G. Boldman, and L. D. Van Vleck. 1993. Estimates of variances due to direct and maternal effects for growth traits of Romanov sheep. J. Anim. Sci. 71:845-849.

Mavrogenis, A. P., A. Louca, and O. W. Robison. 1980. Estimates of genetic parameters for pre-weaning and post-weaning growth traits of Chios lambs. Anim. Prod. 30:271-276.

Meyer, K. 1989. Restricted maximum likelihood to estimate variance components for animal models with several random effects using a derivative-free algorithm. Genet. Sel. Evol. 21:317-340.

Mousa, E.F.A. 1989. Phenotypic and genetic variation in lamb growth. M.S. thesis. University of Assiut, Assiut, Egypt.

Nitter, G. 1975a. Results of crossbreeding experiment with sheep for different systems of fat lamb production. I. Reproductive traits. Livest. Prod. Sci. 2:167-177.

Nitter, G. 1975b. Results of crossbreeding experiment with sheep for different systems of fat lamb production. II. Growth and carcass traits. Livest. Prod. Sci. 2:179-190.

Notter, D. R. 1998. Genetic parameters for growth traits in Suffolk and Polypay sheep. Livest. Prod. Sci. 55:205-213.

Notter, D. R., and J . D. Hough. 1997. Genetic parameter estimates for growth and fleece characteristics in Targhee sheep. J . Anim. Sci. 75:1729-1737.

Olson, L. W., G. E. Dickerson, and H. A. Glimp. 1976. Selection criteria for intensive market lamb production: Growth traits. J . Anim. Sci. 43:78-89.

Robison, O. W. 1981. The influence of maternal effects on the efficiency of selection. A review. Livest. Prod. Sci. 8:121.

Shi, M. J ., D. Laloe, F. Menissier, and G. Renard. 1992. Estimation of genetic and environmental parameters of preweaning growth and conformation in the French Limousin field data. Proc. 43rd Annu. Mtg. EAAP 1:222 (Abstr.).

Sidwell, G. M., and L. R. Miller. 1971a. Production in some pure breeds of sheep and their crosses. I. Reproductive efficiency in ewes. J. Anim. Sci. 32:1084-1089.

Sidwell, G. M., and L. R. Miller. 1971b. Production in some pure breeds of sheep and their crosses. II. Birth weights and weaning weights of lambs. J. Anim. Sci. 32:1090-1094.

Smith, S. P., and H.-U. Graser. 1986. Estimating variance components in a class of mixed models by restricted maximum likelihood. J. Dairy Sci. 69:1156-1165.

Stobart, R. H., J. W. Bassett, J . C. Cartwright, and R. L. Blackwell. 1986. An analysis of body weights and maturing patterns in western range ewes. J. Anim. Sci. 63:729-740.

Tosh, J . J ., and R. A. Kemp. 1994. Estimation of variance components for lamb weights in three sheep populations. J. Anim. Sci. 72:1184-1190.

Waldron, D. F., D. L. Thomas, J. M. Stookey, T. G. Nash, F. K. McKeith, and R. L. Fernando. 1990. Central ram tests in the midwestern United States: III. Relationship between sire's central test performance and progeny performance. J. Anim. Sci. 68:45-53. 